\title{
Initial Building Investigations at Aberdeen Proving Ground, Maryland: Objectives and Methodology
}

Energy Systems Division Argonne National Laboratory 


\section{Argonne National Laboratory}

Argonne National Laboratory, with facilities in the states of Illinois and Idaho, is owned by the United States Govemment, and operated by the University of Chicago under the provisions of a contract with the Department of Energy.

This technical memo is a product of Argonne's Energy Systems (ES) Division. For information on the division's scientific and engineering activities, contact:

Director, Energy Systems Division

Argonne National Laboratory

Argonne, Illinois 60439-4815

Telephone (708) 252-3724

Presented in this technical memo are preliminary results of ongoing work or work that is more limited in scope and depth than that described in formal reports issued by the ES Division.

\section{Disclaimer}

This report was prepared as an account of work sponsored by an agency of the United States Govemment. Neither the United States Govemment nor any agency thereot, nor any of their employees, makes any warranty, express or implied, or assumes any legal liability or responsibility for the accuracy, completeness, or usefulness of any information, apparatus, product, or process disclosed, or represents that its use would not infringe privately owned rights. Reference herein to any specific commercial product, process, or service by trade name, trademark, manufacturer, or othenwise, does not necessarily constitute or imply its endorsement, recommendation, or favoring by the United States Govemment or any agency thereof. The views and opinions of authors expressed herein do not necessarily state or reflect those of the United States Government or any agency thereof. 


\section{DISCLAIMER}

Portions of this document may be illegible in electronic image products. Images are produced from the best available original document. 


\section{Initial Building Investigations at Aberdeen Proving Ground, Maryland: Objectives and Methodology}

by K.L. Brubaker, J.M. Dougherty, and L.D. McGinnis

Center for Environmental Restoration Systems, Energy Systems Division,

Argonne National Laboratory, 9700 South Cass Avenue, Argonne, Illinois 60439

Work sponsored by United States Department of Defense, United States Army, 
This document is printed on recycled paper. 


\section{Contents}

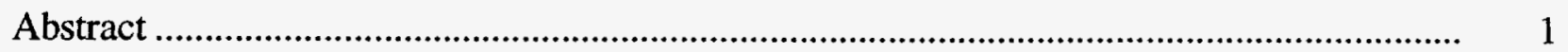

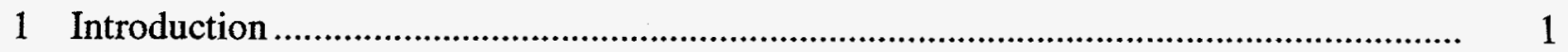

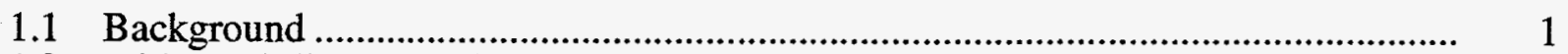

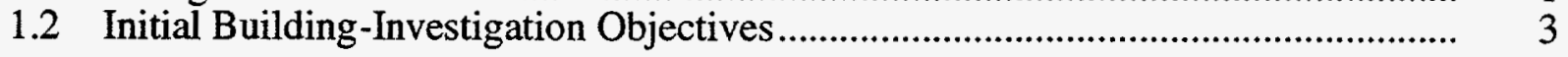

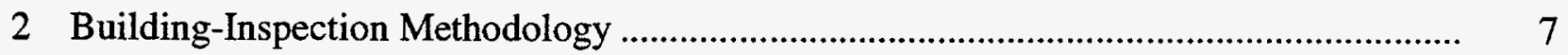

2.1 Historical Records Search .............................................................................. 7

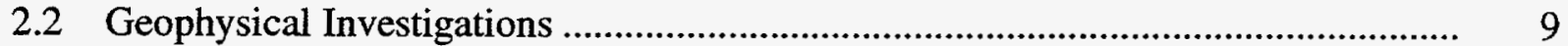

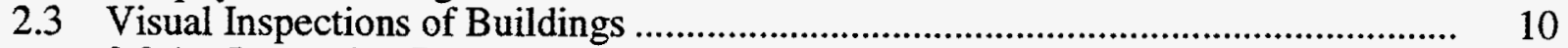

2.3.1 Inspection Personnel ............................................................................... 10

2.3.2 Methodology .............................................................................. 10

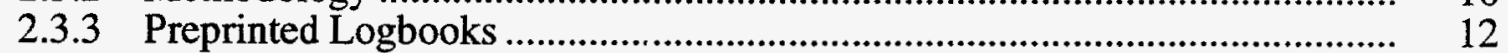

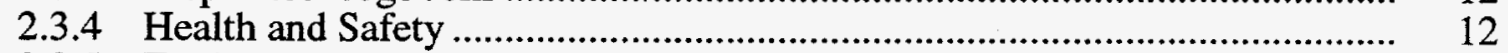

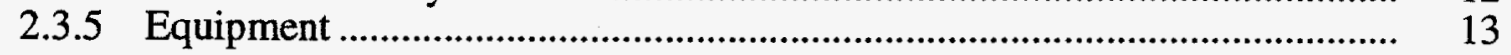

3 Format of the Building-Inspection Report ...........................................................

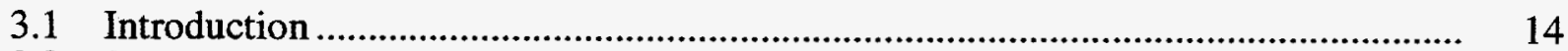

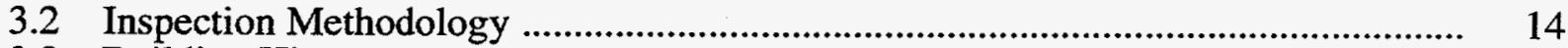

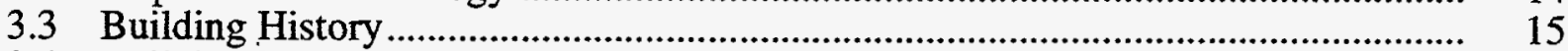

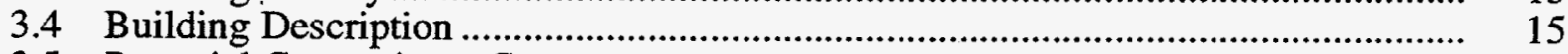

3.5 Potential Contaminant Compartments ......................................................... 17

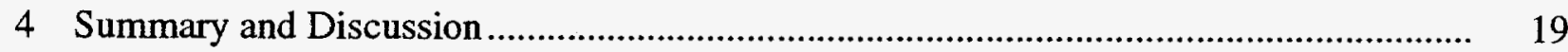

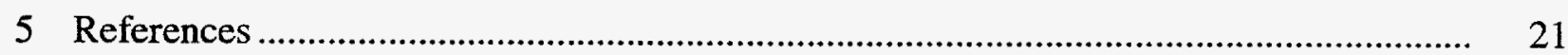

Appendix: Sample Building-Inspection Logbook Pages ......................................... 23

Figures

1 Map Showing the Location of Aberdeen Proving Ground ............................................ 2

2 Site Investigation Process for Potentially Contaminated Buildings at Aberdeen Proving Ground 


\title{
Initial Building Investigations at \\ Aberdeen Proving Ground, Maryland: Objectives and Methodology
}

by

K.L. Brubaker, J.M. Dougherty, and L.D. McGinnis

\begin{abstract}
As part of an environmental-contamination source-definition program at Aberdeen Proving Ground, detailed internal and external inspections of 23 potentially contaminated buildings are being conducted to describe and characterize the state of each building as it currently exists and to identify areas potentially contaminated with toxic or other hazardous substances. In addition, a detailed geophysical investigation is being conducted in the vicinity of each target building to locate and identify subsurface structures, associated with former building operations, that are potential sources of contamination. This report describes the objectives of the initial building inspections, including the geophysical investigations, and discusses the methodology that has been developed to achieve these objectives.
\end{abstract}

\section{Introduction}

\subsection{Background}

The U.S. Army's Aberdeen Proving Ground (APG) is located on Chesapeake Bay in Harford and Baltimore Counties, Maryland, and occupies a total area of approximately 30,000 acres. Figure 1 shows the location of APG and its subdivision into the Edgewood and Aberdeen areas. The primary mission at APG is the testing and evaluation of U.S. Army materiel. Since its beginning in 1917, the Edgewood area of APG has been the principal location for chemical-warfare-agent research, development, and testing in the United States. APG was also the location of chemical-warfare-agent production facilities during the two world wars and has been a center for the storage of chemical-warfare materiel (Nemeth 1989).

Many buildings at APG constructed between 1917 and the 1950s are no longer used because of obsolescence and poor state of repair. Because many of them were used for research, development, testing, and pilot-scale production testing of chemical-warfare agents and other military-unique substances, including incendiary materials and munitions containing these 


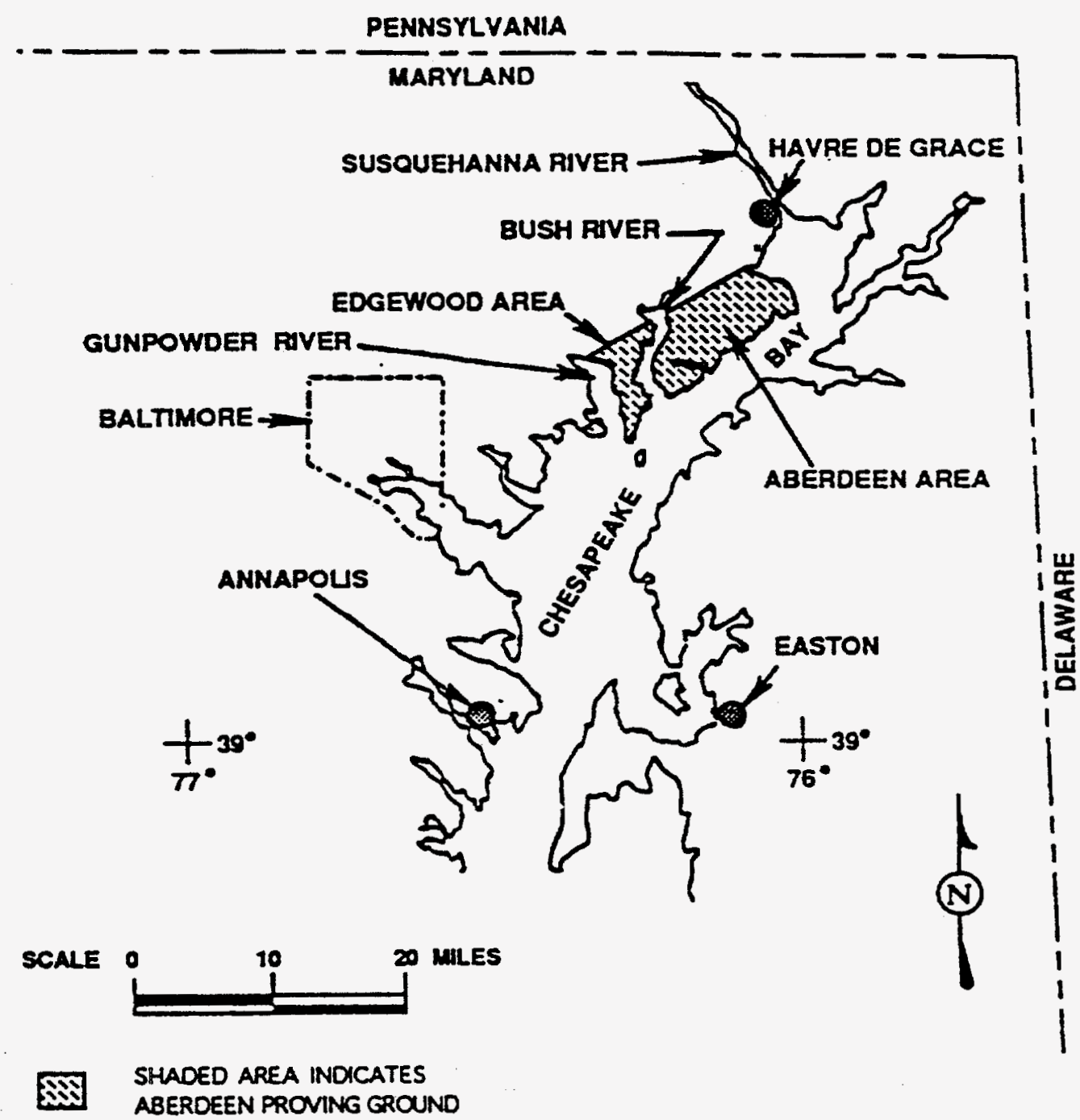

FIGURE 1 Map Showing the Location of Aberdeen Proving Ground

materials, the potential exists for parts of these buildings to be contaminated with these substances, their degradation products, and other laboratory or industrial chemicals. The buildings, together with their associated external structures or appurtenances, including underground or aboveground storage tanks, pipelines, and outbuildings, may contribute to existing environmental problems at APG. Uncontrolled release of hazardous materials during eventual building decommissioning and demolition may constitute an additional threat to human health and safety.

APG has commissioned Argonne National Laboratory (ANL) to carry out a program to address these concerns. Argonne's approach to the problem consists of a multiphase program of investigation for each individual building that includes an initial building-evaluation phase, one or more sampling and analysis phases, and, as funding becomes available, a final demolitionplanning phase. A preliminary risk assessment, assuming that building demolition is an ultimate objective, is prepared in phase one and updated as subsequent phases are executed. After the investigation is completed; a final building-demolition risk assessment can be prepared for use in 
demolition planning and execution. Figure 2 shows the potential sequence of the investigation process for any given building. This flowchart represents more than the actual sequence of steps. The logical flow of information is indicated in that the information required to plan and execute each step is developed in the preceding stages.

As part of the initial evaluation phase, detailed internal and external inspections are being carried out for 23 potentially contaminated buildings, and the subsurface in the vicinity of each building is being investigated using geophysical techniques. This report describes the objectives and methodology for the conduct of these initial building investigations.

\subsection{Initial Building-Investigation Objectives}

The principal objective of the initial investigation is to obtain information necessary for the development of a field sampling plan (FSP) for the initial building-sampling phase and for the development of the preliminary risk assessment. A secondary objective is to gather information about the structure that will be required in planning for the potential eventual demolition. Also, the information gathered during the building inspection may assist the Army in complying with the requirements of the National Historic Preservation Act (1966), as amended, and its associated regulations. The inspection report documents the existing state of the building and its contents at the time of the inspection.

More specifically, the objectives of the building inspection, including the geophysical study, are as follows:

1. To identify all potential "compartments" in which contaminants of concern may be present;

2. To document the location, dimensions, physical condition, accessibility, and any other relevant attributes of each compartment;

3. To collect information about the design and construction of the building that is needed for the final demolition plan;

4. To locate, identify, and obtain copies of historical records that provide additional information regarding the potential location of contamination within and near the building, as well as information pertaining to the design and construction of the building and its support systems (heating, ventilation, and air conditioning [HVAC]; sewage; electrical power; water; and other specialized systems, such as steam, compressed gas, etc.); and 


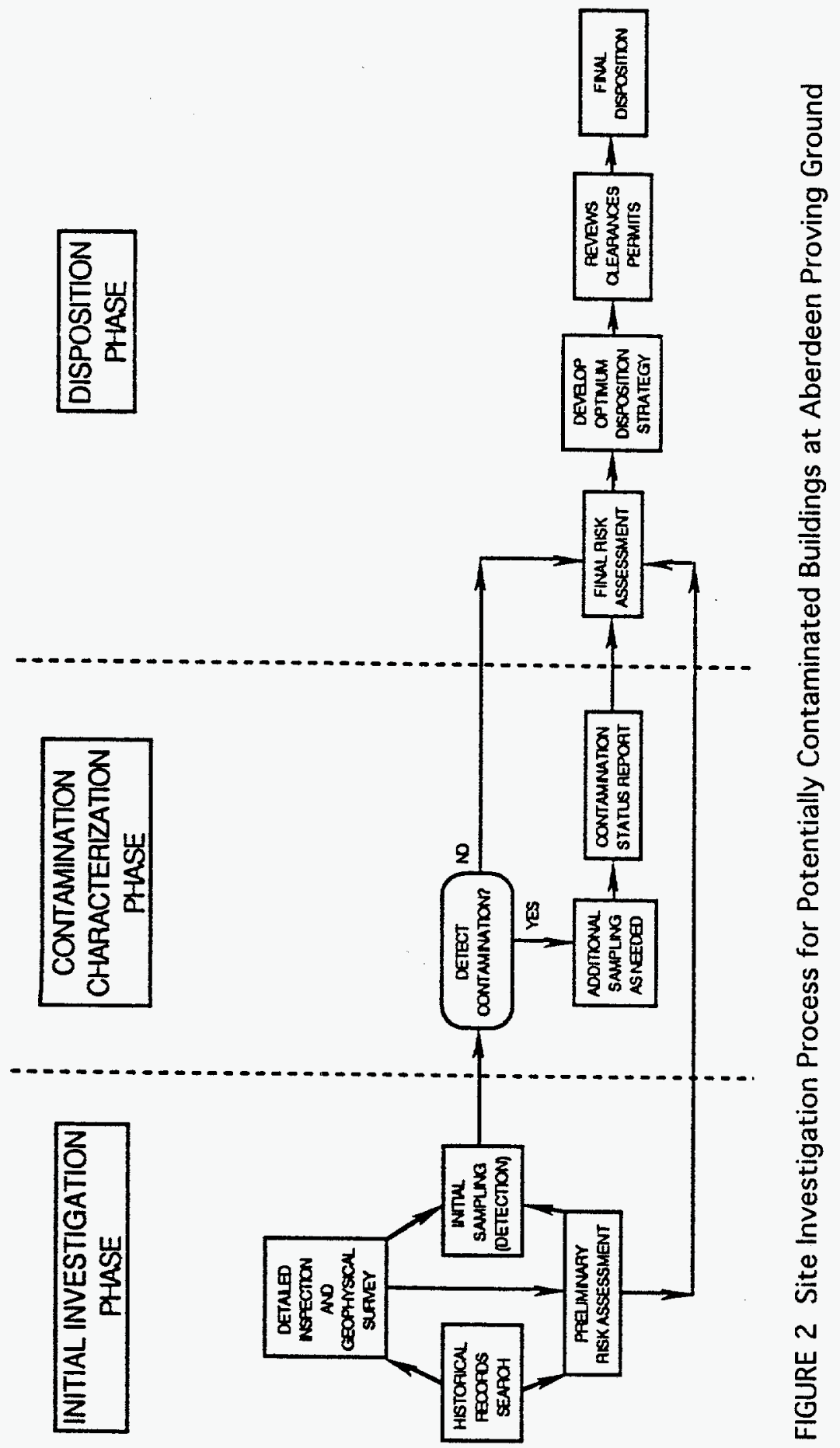


5. To produce a report documenting the findings of the inspection team for future use in developing the FSP, the preliminary risk assessment, and the demolition plan.

In this context, the term compartment denotes any generic or specific location or medium in which contamination may be found. The following is a partial list of potentially contaminated compartments in and around buildings or other structures:

1. Interior of the building

a. Ventilation system - ducts, filters, blowers, vents, screens, hoods, etc.;

b. Sanitary sewer and other drainage systems - collection points, such as traps, sumps, and low areas in lines; areas below the floor in the vicinity of the underground drainage system;

c. Process-related equipment - piping, tanks, pumps, etc. that are still present; and

d. Potential spillage areas*

(1) Floors - cracks, collection points, low areas, high-spill-probability areas;

(2) Walls (up to approximately $8 \mathrm{ft}$ above floor level) - nonporous as well as porous materials in high-spill-probability areas;

2. Exterior to the building

a. Underground tanks, process pipelines, and other such underground process-related structures;

b. Sumps;

c. Ditches and drainage channels, especially near points at which releases from inside the building may have occurred;

\footnotetext{
The nature of the material in an area subject to spillage is important because porous materials could contain contamination. Porous materials include cement, grouting, wood, and wallboard. Nonporous materials may still retain certain types of contamination on their surfaces.
} 
d. Areas in the immediate vicinity of underground drainage and sewer lines;

e. Areas in and around concrete pads (transformer pads, storage areas, etc.);

f. Areas in the vicinity of major electrical connections/components; and

g. Areas in the vicinity of aboveground storage tanks and process-line connections with adjacent buildings. 


\section{Building-Inspection Methodology}

The activities required to produce the building-inspection report can be grouped into four steps: (1) the conduct of a historical records search, (2) the detection and investigation by geophysical methods of any underground structures associated with the building, (3) the conduct of a detailed visual inspection of the internal and external areas of the building, and (4) the consolidation of the information gathered in steps 1-3 into a final inspection report.

A preliminary visit to the site prior to the actual inspection visit can be useful. The objectives of the preliminary visit are to obtain engineering drawings for the buildings to be inspected, to identify health and safety issues that need to be addressed, to discuss and resolve any access restrictions, to identify all required support services, and to identify any potential problems that might hinder the execution of the inspection or the geophysical investigation. Photographs taken of the exterior of the building are useful in planning the actual inspection visit. Before taking photographs at APG, the team must obtain a camera pass. All exposed film must be submitted to APG, where it is developed and the photographs are scrutinized by a censor prior to release. Adequate time must be allowed for these steps in scheduling the work.

Following the preliminary site visit, an inspection work plan and an associated health and safety plan are prepared for each of the buildings to be inspected. After APG review and approval of these plans, the inspection can be conducted. Because of scheduling constraints and other considerations, Argonne prepared separate work and health and safety plans for the geophysics investigations, which take place entirely out-of-doors, and for the building inspections, which take place largely inside. It is desirable but not essential that the geophysics investigation be conducted simultaneously with the visual inspection; currently, separate teams of ANL staff are involved in these two activities.

\subsection{Historical Records Search}

The historical records search for a given building has at least two objectives. The principal one is to determine, as completely as possible, the uses to which the building has been put over the years since its construction and, thereby, to identify all chemical contaminants that might be present which might pose a threat to human health and safety or to the environment. The chemicals of concern may include warfare agents or other military-unique materials; chemicals used in agent or munition production; chemicals used in the maintenance of equipment (for example, degreasing solvents); agent or other degradation products; and industrial chemicals associated with the specific operations carried out in the building.

A secondary objective of the historical records search is to obtain engineering drawings, photographs, and other documents pertinent to the building and its associated systems. It is also important to obtain any drawings showing the location of utility lines, especially drainage and sewer lines, external to the building. Engineering drawings are required to understand where the various operations were carried out within and exterior to the building, and to identify building 
modifications made during any change of operations. This information should be as detailed as possible, in particular as it relates to potential contaminant compartments. If structural modifications have been made to a building, it is desirable to have building drawings that span the entire period of operation, not only the most recent configuration. Engineering drawings are also useful in planning the inspection visit and are essential in developing an inventory of potentially contaminated compartments and their locations.

The type of records available for a given building depends on the nature of the operations that were carried out in the building. For buildings used for chemical research, development, testing, and production, the following may be a reasonably typical list of records that might exist: technical reports, annual progress reports, laboratory summaries, laboratory notebooks, inventories, shipping and receiving records, production logs and summaries, internal memoranda, maps, real property records, engineering drawings of the building and its component systems, and drawings showing utility lines in and around the building.

In addition to these specific sources, other general historical reports and documents, including base histories, are often useful, as are personal interviews with building custodians and other current or former employees that worked in the building. Personal interviews often yield valuable information about operating procedures or such happenings as accidents or spills that may not be well-documented. This type of information often cannot be corroborated, however, and may not always be reliable.

Aerial photographs represent another type of historical record that can be useful in certain situations. A sequence of aerial photographs that spans a significant period of time can often provide important information about the location and spatial extent of activities and structures of interest. For example, the location of former storage tanks or disposal areas can often be determined most accurately from aerial photographs. Sources of aerial photos for U.S. Army facilities include base historical archives and museums, archives in base environmental or forestry offices, and the series of reports prepared by the Environmental Photographic Interpretation Center (EPIC) of the U.S. Environmental Protection Agency (EPA), under contract to the U.S. Army Toxic and Hazardous Material Agency.

Prior to Argonne's involvement in the source-definition and building-decommissioning work at APG, the Chemical Research, Development, and Engineering Center (a tenant organization at APG responsible for the bulk of the research, development, and testing of chemical warfare materiel) commissioned a historical records search on 29 unused buildings (EAI Corporation 1989). This list of 29 has been somewhat modified since the inception of the ANL program, but it has served for the most part as the primary working list of buildings to be decommissioned and eventually demolished. The EAI report has been made available to ANL, so a separate historical records search has not been conducted for these buildings. However, ANL has obtained copies of all available engineering drawings for each building examined, as well as a collection of aerial photos, including the EPIC report for APG. Another extremely useful source of information about buildings at APG has been the RCRA Facility Assessment Report (Nemeth 1989). 


\subsection{Geophysical Investigations}

The primary objectives of the geophysical measurement program conducted during the initial building-investigation phase are to detect and to describe the location and geometry of exterior subsurface compartments by nonintrusive measurements. The primary compartments targeted by this program represent subsurface structures that were associated with operations carried out in the subject building. Another objective is the detection and mapping of electrically anomalous pore fluids that may have entered the subsurface because of releases in or near the perimeter of the building in question. After a preliminary site visit, the extent of the area to be surveyed is determined. The area selected is governed by the size and nature of the open space surrounding the subject building. Such cultural or natural features as lawns, fencing, creeks, wetlands, and shorelines that are present are factors in the areal determination. Other criteria, including proximity to nearby buildings, also contribute to the decision.

Many of the buildings listed for decommissioning contain a large amount of metal in the form of corrugated-steel siding and roofs, structural steel members, and steel reinforcing in the concrete foundations and slabs. Buildings are often linked to each other by a system of metal overhead steam or other pipes, as well as by underground utility lines. Steel grates, fill used to raise the grade in lowland areas, and steel doors on many buildings all contribute to significant near-surface interferences to such common geophysical measurement techniques as electromagnetic (EM) induction methods.

Experience gained during geophysical investigations conducted in 1991 and 1992 led to a refinement of the instrumentation needs and the development of a specially designed field program. Equipment was designed and selected to permit rapid acquisition of data near metal buildings, over grass-covered areas, and over concrete slabs, gravel, and other, similar materials.

Techniques applied to building-related studies include a presurvey sweep for near-surface ferrous metal objects using a magnetic gradiometer. These gradiometer measurements are used to outline anomalous areas prior to magnetic surveying along transects spaced 5 - $\mathrm{ft}$ apart. The magnetometer is operated in a continuous mode with readings taken every $0.1 \mathrm{~s}$. Magnetic measurements are followed by EM measurements, horizontal resistivity profiling, and groundpenetrating-radar measurements over magnetic lines. Magnetic and electrical coverage permits determination of the presence and location of ferrous and nonferrous conductive materials in the subsurface. In addition, electrical induction and resistivity mapping provide data on the presence and distribution of relatively conductive or resistive regions that may indicate the presence of leachate plumes emanating from the subject building. Finally, the geometry and spatial relationships of anomalous sources are characterized using ground-penetrating-radar imagery. New technologies and methods are incorporated into the geophysical program as instrumentation and programmatic needs evolve.

Data presentation and interpretation are enhanced through the use of color graphics. Superposition of magnetic-field contours on colored representations of electrical properties results in maps of the material properties that can be viewed immediately. Radar imaging over 
magnetic and electrical features quantifies depths to the tops and horizontal limits of anomalies. A combination of geophysical interpretations, historical records, and inspection of building interiors results in the best possible description of the subsurface exterior to buildings.

Experience to date shows that geophysical investigations are useful in locating suspect areas and in confirming the presence of underground structures for which other evidence is available.

\subsection{Visual Inspections of Buildings}

\subsubsection{Inspection Personnel}

In order to identify all potentially contaminated compartments, it is important to know as much as possible about the building and its component systems. It is also important to determine, if possible, the function of any equipment, pipelines, and other structures still in the building. Deductions must often be made on the basis of a combination of observations and historical information, and detailed engineering drawings are often not available. On-site judgements must be made regarding what is or may be a significant feature or attribute. For these reasons, in order to maximize the information obtained from the inspection, it is essential that the building-inspection team contain personnel experienced and knowledgeable in building construction and general mechanical-equipment operations, as well as in the general type of operations that are believed to have been carried out within the building. It is desirable for at least one team member to be knowledgeable in field sampling techniques and experienced in the preparation of FSPs and/or risk assessments. It is essential for best results that the person who will be responsible for the preparation of the inspection report be a member of the inspection team. This person should actively supervise the entry of information into the field logbook and direct the taking of photographs. Argonne building-inspection teams for the APG program typically consist of two or three individuals; more than one team may be assigned to a given building, depending on its size and complexity.

\subsubsection{Methodology}

The visual building inspections at APG are carried out in a detailed, systematic, and nonintrusive manner. The following sequence of activities has been found to work well:

1. Document the environmental setting, the location, and the nature of any significant external object, structure, or feature.

2. Document the exterior dimensions of the building and the location, dimensions, and other characteristics of any exterior structure. If this 
information is not already available on engineering drawings, record the size and location of all openings (doors, windows, exhaust-fan ports, etc.) in each outside wall of the building. Note the position, size, and connections of any pipe, stack or other object penetrating the walls or roof. Also, document the exterior condition of the building and the structural materials used.

3. Examine the exterior and local environment of the building for potential contamination compartments (in conjunction with the geophysical survey team, if possible). Document the location and all other significant attributes of any external object, structure, or feature identified as a potential source or location of contamination.

4. Proceed systematically throughout the building interior, working from a prepared floor plan, if possible. Document the location, dimensions, condition, type of structural materials used, etc., for each room of the building.

5. Examine each room of the building for potential contamination compartments. Document the location, size, and any other significant attributes of each potential compartment identified. Document the presence and identify, as far as possible, the nature of all pipes, ducts, vents, and other features of utilities or process equipment present. Note the position, size, and connections of any pipe, stack, or other object penetrating the floor, walls, or ceiling. (During the inspection, it is useful to trace pipes and other connections leading from one room to another, in order to understand their function. Thus, it is important to document the characteristics [type, size, color, etc.] of each pipe leading into or out of each room, as well as into or out of the building as a whole.) Identify, as far as possible, the nature of the operations conducted in each room. (Clues to the nature of these operations may be found in structural features, including the room configuration and layout, as well as in any pipes, vents, or equipment that remains.)

6. Upon returning from the inspection visit, collect and examine materials and documents relevant to the building, determine findings and conclusions to be drawn, and document these in the building-inspection report.

Observations are documented both by hand in a field logbook and photographically. It has been found from experience that photography is the most useful type of documentation for recording such complex situations as mechanical features, plumbing configurations, and complicated structural features, because a great amount of detail can be recorded easily. Photography is also useful for documenting specific significant details. It is important to take what may seem to be an overabundance of photographs, because several photographs taken from different points of view are often required to fully document complex configurations of pipes, process equipment, ventilation ducts, and other systems. The field logbook is essential for documenting architectural features, dimensions and distances, building materials, floor plans and 
footprints, and important general and specific observations (for example, those pertaining to discolored and potentially contaminated areas).

The inspection team must be methodical and comprehensive, because much of the interpretation of the field observations is carried out subsequent to the field trip, and details that might not seem significant at the time are often very useful when the inspection report is being prepared. Typically, one member of the inspection team is responsible for keeping the logbook, at least within a given room. Before leaving that room, another member of the team reviews the logbook entries and sketches to ensure that everything of significance has been duly noted. Individual task responsibilities can be rotated as the team progresses from one room to the next in order to even out the work.

\subsubsection{Preprinted Logbooks}

It is desirable to standardize the process of collecting and recording building information in order to increase the efficiency with which building-inspection reports are prepared. Standardization is also necessary to ensure that important information is not inadvertently overlooked by the building-inspection team. In order to achieve the desired uniformity and standardization and to provide suitable guidance to the inspection team, preprinted logbooks have been developed for each building. A few examples of preprinted logbook pages appear in the Appendix. Each logbook is divided into the following major sections: site plan information, exterior elevation information, roof information, and information for each room. Subsections for the room information are interior elevation information, floor-plan information, and ceiling information. Each of these categories contains a number of subcategories, depending on the size and complexity of the subject building. A number of headings in the form of questions are incorporated into each of the logbook pages. These questions guide the field survey team as the members collect the data for each of the subject buildings; a response to each question is entered into the logbook. If any question or heading does not apply to the subject building, the field investigator enters NA, meaning not applicable. Provision is also made for sketches that correspond with the logbook pages for each room of the subject building. These field-generated figures are drawn on 1/4-in. quadrille paper incorporated into the logbook and potentially can include room elevations as well as ceiling and floor plans. The final heading on each of the preprinted pages is "Other Notes." This space is intended for recording information concerning items that appear in the study area which are not specifically addressed by the logbook headings. The data-collection process is aided by the extensive photo study conducted for each room of the building.

\subsubsection{Health and Safety}

All individuals entering a potentially contaminated building for the purpose of conducting an inspection are required to have satisfactorily completed the standard 40-hour course required by OSHA regulations for hazardous-waste-site workers (OSHA 29 CFR 1910.120, 1987). 
Personnel conducting the geophysical and external visual building investigations are also required to have completed the 40 -hour course.

The building inspections conducted in the APG program are nonintrusive by design, which means that no samples are collected nor are any potentially contaminated compartments disturbed in any way. No confined-space entries are made during the initial inspection. If the inspection team determines that confined-space entries are needed to obtain information necessary for the development of the FSP and preliminary risk assessment, these are planned and scheduled for a separate trip. Depending on the building history and physical condition, various levels of personal protective equipment may be required for entry into the building; the appropriate level must be determined on a case-by-case basis. A physical threat due to deterioration of the physical structure of the building or of its internal structures may be present, in addition to any potential threat from chemical exposure. It is also common for friable asbestos and lead-based paint to be present in older buildings. A minimum level of personal protective equipment lies between U.S. EPA levels 3 and 4 (NIOSH/OSHA/USCG/EPA 1985) for buildings that are no longer in use and are often in sufficiently poor physical condition that their interiors are partially exposed to the weather. The minimum level of respiratory protection used in the APG program is level 3: a half- or full-face-piece respirator with HEPA filter cartridges for protection against dust containing unknown materials, asbestos fibers, lead paint, bird feces, and other potential health threats. In the minimum level of protection, coveralls and work gloves are worn to provide dermal protection, and safety glasses, hard hats, and safety boots with steel toes and shanks are worn to protect against physical injury. At APG, protection against Lymedisease-carrying ticks is also essential and is achieved by taping the ends of the coverall pants and sleeves tightly and using insect repellent on boots and pants.

\subsubsection{Equipment}

Several items of equipment in addition to those required by health and safety concerns have been found useful in conducting building inspections at APG. As indicated above, observations are documented both in a field logbook and photographically. It is essential that each photograph be properly identified. If the camera can record a caption directly on the photograph, this feature can be used together with corresponding field notes. A less desirable alternative is to place a sheet of paper with a sequential number or other suitable caption into the view being photographed. A combination of both techniques may be useful in complex cases. Tape measures of various lengths are absolutely necessary for measuring dimensions, and expandable measuring rods of the type used in surveying can be placed so as to provide a linear scale when making photographs of the area. Flashlights are essential for illuminating interior rooms or other dark places. Walkie-talkies allow two or more inspection teams to keep in touch when separated. A portable cellular telephone allows an inspection team to contact emergency medical support personnel in the event of a medical emergency or to contact other support personnel, as needed, in a timely and convenient manner. 


\section{Format of the Building-Inspection Report}

This section describes the format used in preparing the building-inspection report and illustrates the level at which the information should be presented. It has been Argonne's practice to prepare one report describing the results of the geophysical study and a separate report describing the results of the visual inspection for each APG building investigated. This practice is not essential, and the preparation of a combined report would have certain advantages. The format currently used in the visual building inspection reports is presented in this section.

The conclusions drawn from the building inspection and the geophysical studies should be presented so as to provide the maximum amount of information relevant to the overall objective of determining the locations and other features of potentially contaminated compartments. It has been found from experience that detailed drawings (accompanied by notes as required), rather than photographs, are best for this purpose, even though the preparation of the necessary drawings is time-consuming if engineering drawings are not available or are inadequate. Drawings allow the relevant features to be clearly displayed and the irrelevant features to be de-emphasized. Once completed, the drawings can be easily modified for use in the FSP, the preliminary risk assessment, and other documents. Carefully prepared drawings also focus attention on the important details and appear to be the best mechanism for ensuring that the list of potentially contaminated compartments is comprehensive and complete. When suitable engineering drawings are available, these may be used and modified as needed.

Specific guidance for the preparation of building-inspection reports follows in the remainder of this section.

\subsection{Introduction}

A brief introduction to the project as a whole should be provided. The various stages of the project for each building should be described, indicating the logical position of the initial building investigations of which the building inspection is a part. This information is expected to be nearly identical in all APG-building-inspection reports and is similar to that found in the introduction to this report. The building that is the subject of the report should be specified (name and/or number), and the dates during which the building inspection and the geophysical study were carried out should be given.

\subsection{Inspection Methodology}

A brief description of the methodology used in carrying out the building inspections should be given. This information can be obtained from this report and is nearly identical for each building at APG. 


\subsection{Building History}

The results of the historical records search should be presented or summarized, as appropriate. Maps showing the location of the building within APG and the position and orientation of the building with respect to its immediate surroundings, including nearby roads and other buildings, should be included. Additions or alterations that may have been made to the building should be described, including dates and reasons for the modifications, if known.

\subsection{Building Description}

The results of the visual building inspection should be presented. This description will generally extend over several sections. The format for the building-description portion of the final report should be similar to that of the preprinted logbooks, so that the information in the logbook for each building may be easily incorporated.

A general description of the building should be given, including overall dimensions, type of construction, and construction materials used in the foundation, exterior walls, and roof. The overall condition of the building and any areas considered physically hazardous because of deterioration of the main building structure should be described.

A detailed external site plan, showing a footprint of the building and all significant features near the building, should be provided. The site plan should be dimensioned, drawn to scale (if possible), and show all aboveground utilities. Topographical aspects of the site should be indicated, noting such natural or manmade low areas as drainage ditches, exterior sumps, french drains, depressions, etc.

Underground structures detected by the geophysics investigation should be indicated, either on the plot plan or on a separate figure. Underground utility points of access, including manhole covers, utility vaults, underground storage tanks, and catch basins; underground pipelines; and any unexplained geophysical anomalies should be noted.

Such geographic characteristics as wetlands, forested areas, and areas of dense vegetation should be shown, as well as roads, sidewalks, loading areas, parking lots, exterior storage tanks, railroad tracks, and, in general, all man-made structures near the building. Any areas of stressed vegetation or areas that appear to be stained by a substance should also be shown. The text that accompanies the plot plan should point out and discuss the potential significance of each feature, especially any that may be a source or a location of contamination.

Figures showing the external building elevations should be provided and all significant features should be indicated in full detail. The overall dimensions of each exterior wall of the building should be indicated. A detailed description of all external attributes of each wall, including all openings and all pipes, vents, or stacks leading into or out of the building, should be 
provided. Any evidence of piping that may have been removed, such as holes in the exterior skin of the building or disconnected pipes, should be noted. Pipes that exit the building and enter the ground may be of special concern, depending on their connections in the building interior. Areas of the building that are stained, discolored, corroded, or deteriorated should be indicated. Note all utility connections and their status. Special appurtenances that are attached or are adjacent to the building, including electrical panels and disconnects, or equipment located outside the building that may have been associated with building operations should be shown.

Figures showing the overall floor plan for each floor of the building should be provided. These figures should be dimensioned, and each room should be assigned a unique number or other designation. If the most recent room-numbering scheme used by APG is known, this scheme should be used. In the absence of an APG room-numbering system, the following system should be adopted. Each of the floors of the building is numbered sequentially upwards. For example, the ground floor is denoted as level 1, the second floor as level 2, and so on. Each room in the building is designated by a unique three-digit number that incorporates the floor number as the first digit. The second and third digits provide a room specification unique to that floor. The room numbers on each floor of the building are assigned in a systematic manner, and if the floor plans of two adjacent levels are similar, the room-numbering scheme should reflect this similarity. If a high-bay area exists, it should be numbered as a room corresponding to the appropriate floor level. Basement levels are designated by the prefix B. If possible, the location of drainage or other building systems that lie below the lowest level should be shown; this information may only be available from engineering drawings, if it is available at all.

For each room, diagrams showing all significant features within the room, including wall elevations, should be provided as needed; examples of likely diagrams are ceiling plans, detailed floor plans, and diagrams of equipment or other special features present. At a minimum, a dimensioned floor plan for each room should be provided. Cross-reference the drawings for clarity. The accompanying text should give a detailed description of the room, including the structural materials used for the floor, walls, and ceiling. If available, a description of the operations that were carried out in the room should be given. Rooms that were clearly intended to be isolated for containment, safety, or other reasons are of particular interest as potential contamination locations, so any special aspect or feature of the room that provides a clue to its use should be described. The likely operations that are known or believed to have been conducted in each room should be discussed.

Areas of the interior that show signs of possible chemical exposure, for example, severe corrosion or discoloration, should be noted. The location of all remaining processing equipment and supplies, as well as all drains, including floor, equipment, roof, and condensate drains, open sumps, and troughs should be shown. Note evidence of equipment that has been removed, such as hoods or ductwork that remain as remnants.

In some cases it may be desirable to prepare separate drawings and descriptions of such building mechanical systems as HVAC or plumbing, including domestic and sanitary drainage. The following specifications relate to these systems. 
For the HVAC system, all duct work present in the building should be shown, including all air-handling units that are part of the system (these are fans or air-conditioning units that are integrated into the duct work). These units should be assigned a unique code designation for identification purposes. Examples of these designations are AHU\#1 for air-handling unit number one; RTU\#3 for rooftop unit number three; EF\#2 for exhaust fan number two. All areas where air filters are installed into the HVAC system should be shown, noting the presence of corrosion on or within the ductwork. All air-filtration units should be shown and described in detail, giving size, type, and location with respect to air-handling units (upstream or downstream).

Air scrubbers or air-filtering systems that are present should be described, giving makes and models, if available. A detailed description of each should be provided, including size, number of converging ducts, how each is connected into the system, the location and characteristics of all wastewater streams, including condensate lines, noting location, size, and type of filter media. The condition of the equipment should be described, noting any evidence of corrosion or decay.

The plumbing systems within buildings used for research, development, and testing can be quite complex, and it is recommended that different systems be segregated and described separately. Each system must be identified; possible systems include domestic water supply, fire-sprinkler water supply, domestic or sanitary drains, chemical transmission lines, chemical drains, compressed air or other compressed gas systems, and steam lines. Not all of these may be of interest as potential contaminant compartments in every case.

Holding tanks should be described in detail. Note if inlet and drain piping for these tanks remains intact. The type of tank construction, continuously welded or riveted plate, should be noted. Components of the plumbing systems, including pumps, valves, condensate bulbs, pressure-reduction valves, sediment legs, temperature and pressure gauges, drain cocks, dialectic connections, and plumbing fixtures should be described in detail. The type of connections used (threaded [right- or left-handed], continuously welded pipe, compression connections) and the pipe material and size (steel, cast iron, copper, galvanized steel, aluminum, clay, PVC) should be noted. Areas where systems appear to be cross-connected should be described in detail; an example might be chemical drains being piped directly into the domestic or sanitary drainage system. Note any signs of corrosion or discoloration. Signs that the system has been modified should be noted, including distinctly different pipe incorporated into an otherwise uniform system, unpainted or raw pipe connected to painted pipe, or areas of the system that appear to have been abandoned or capped off. The presence of insulation that may contain asbestos should be noted, and the condition of the insulation should be described.

\subsection{Potential Contaminant Compartments}

Following the detailed building description, the report should list all potentially contaminated compartments that were identified as a result of the building inspection and the geophysical investigation, keeping in mind that the information provided will form the basis for 
development of an FSP. The following information should be provided for each potentially contaminated compartment:

- Description of such visual evidence of contamination as staining, discoloration, or corrosion;

- Identifying marks or labels that provide relevant information;

- List of potential chemical contaminants that may be present;

- Information regarding the compartment that could not be obtained during the inspection but which is needed for the development of an FSP; and

- Qualitative judgment as to the relative likelihood that the given compartment may be contaminated; in many cases, the reasons for considering a particular compartment may be obvious, but in other cases, more detailed justification may be needed.

In addition, the possibility of contamination of certain building systems or structures may be considered so unlikely that these items are not included in the list of potentially contaminated compartments. In some cases, compartments that might be identified as potentially contaminated on the basis of a superficial analysis may not be included in the final list; in these cases, an appropriate justification for their exclusion should be provided. 


\section{Summary and Discussion}

The conduct of a detailed visual building inspection and a geophysical investigation of nearby subsurface features are essential early parts of the multiphase program developed by ANL to address environmental and health and safety issues associated with potentially contaminated buildings at APG. This report has described the objectives and methodology used in conducting these investigations, provided guidance for the conduct of such studies on the basis of experience at APG, and suggested an appropriate format for the building-inspection report that is the final product.

The methodology and suggestions presented in this report are based on the experience gained to date in investigating 11 buildings at APG. Each building has been found to be unique in some way, and experience has shown that in order to fully attain the desired objectives, the inspection team must comprise personnel of diverse backgrounds and experience. The operations carried out in each building must be understood well enough to identify all potentially contaminated locations within and external to the building. This understanding is usually achieved only through a process analogous to solving a puzzle, because most, if not all, of the process equipment has long since been removed, and engineering and architectural drawings are often inadequate or not available. All available information and the clues remaining in the building must be considered in compiling the final set of potentially contaminated compartments. This interpretation process requires personnel knowledgeable of past and current buildingconstruction practices, typical building-system configurations, process machinery and its operation, and the chemical operations that are known to have been carried out in the building.

Extensive documentation of building features is also required and is best achieved through the extensive use of photography. On the basis of experience to date, approximately $75 \%$ of the information contained in the final reports is documented in photographs and about $25 \%$ through the data and notes in the field logbook. The use of modern data-acquisition and data-processing capabilities is crucial for the efficient acquisition, processing, and interpretation of geophysical data. Specialized equipment may need to be designed and fabricated, as was done at ANL to increase significantly the rate at which resistivity data were collected.

The results are best presented in the inspection report through the incorporation of detailed drawings, either newly prepared drawings or the existing engineering drawings (if available). Although drawing preparation can be a time-consuming operation, significant features can be clearly presented and given the desired emphasis. Also, because the drawings are assumed to be made using appropriate computer software, they can easily be modified for use in such other documents as the FSP, the preliminary and other risk-assessment documents, and, ultimately, any building demolition planning documents.

It should be noted that this current report describes the building-inspection methodology at its present state of development, representing ANL experience from two seasons of work at APG. As further experience is gained, the recommended procedures may be modified because, as noted above, each new building seems to be unique in certain ways. New situations will 
undoubtedly be encountered. At this time, however, the contents of this report represent the best available guidance known to us on the issue of how to identify potentially contaminated areas within and around buildings. 


\section{References}

EAI Corporation, 1989, Historical Records Search and Site Survey of Edgewood Area Buildings, Final Report, prepared for U.S. Army Chemical Research, Development, and Engineering Center, Aberdeen Proving Ground, Md., under contract No. DAA15-87-D0021.

Nemeth, G., 1989, RCRA Facility Assessment Report, Edgewood Area, Aberdeen Proving Ground, Maryland, prepared by U.S. Army Environmental Hygiene Agency.

NIOSH/OSHA/USCG/EPA: see National Institute for Occupational Safety and Health, Occupational Safety and Health Administration, U.S. Coast Guard, and U.S. Environmental Protection Agency

National Institute of Occupational Safety and Health, Occupational Safety and Health Administration, U.S. Coast Guard, and U.S. Environmental Protection Agency, 1985, Occupational Safety and Health Guidance Manual for Hazardous Waste Site Activities, U.S. Department of Health and Human Services, Washington, D.C.

Occupational Safety and Health Administration, 1989, "Hazardous Waste Operations and Emergency Response Standard," Code of Federal Regulations, Title 29, 1910.120 (March 6). 
- Appendix:

Sample Building-Inspection Logbook Pages 


\section{Appendix: Sample Building-Inspection Logbook Pages}

This appendix contains five sample building-inspection logbook pages that illustrate the nature of the information recorded. An inspection logbook consists of an adequate number of each type of page to cover the building being inspected, with extra pages included to allow for various contingencies. Pages of quadrille paper are also interleaved within the other page types to facilitate the preparation of sketches, as shown in the samples. 


\section{Site Description Building E3640}

\subsection{Address:}

1.2 Proximity to other buildings:

1.3 Exterior footprint dimensions:

1.4 Surface soils and topographical conditions:

1.5 Vegetation in the immediate vicinity:

1.6 External aboveground structures or equipment:

1.7 Connections with adjacent buildings: 
1.8 Location and type of underground structures:

1.9 Location and type of surface drainage system:

1.10 Utility access points (manholes) and identify utility type:

1.11 Piping that exits the building and enters the ground:

1.12 Location and direction of nearby roads and sidewalks: 


\section{Building E3640}

Site Plan

Building Number

Date

Sketches By

Reviewed By

Inspection Team 


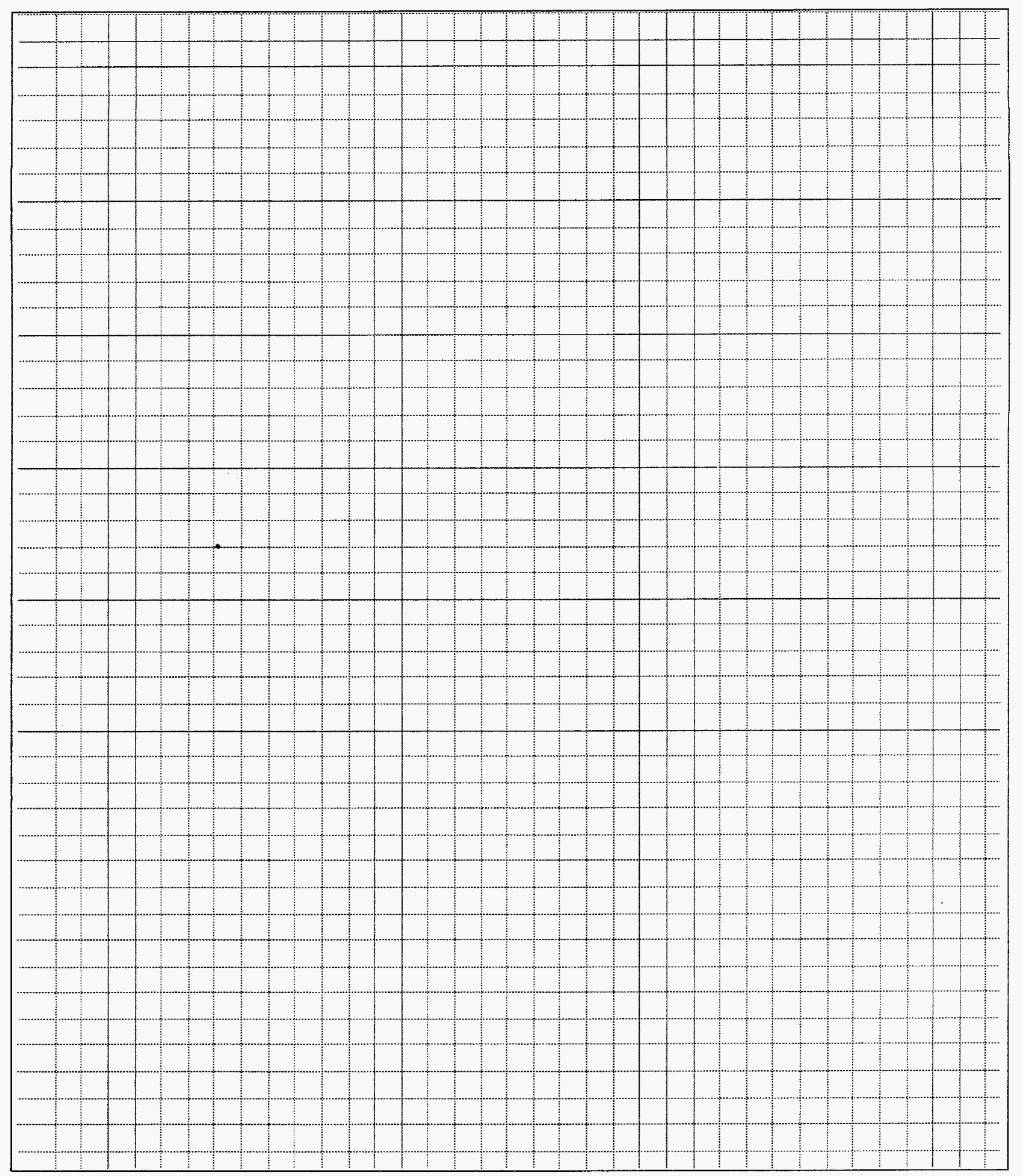




\section{Exterior Elevations E3640}

\subsection{E3640 North Exterior Elevation}

\subsubsection{Dimensions:}

2.1.2 Construction materials:

- 2.1.3 Doors and windows:

2.1.4 Piping along or connected with this face of the building:

2.1.5 Utility connections:

2.1.6 External equipment or structures: 


\section{Building E3640}

North Exterior Elevation

Building Number

Date

Sketches By

Reviewed By

Inspection Team 


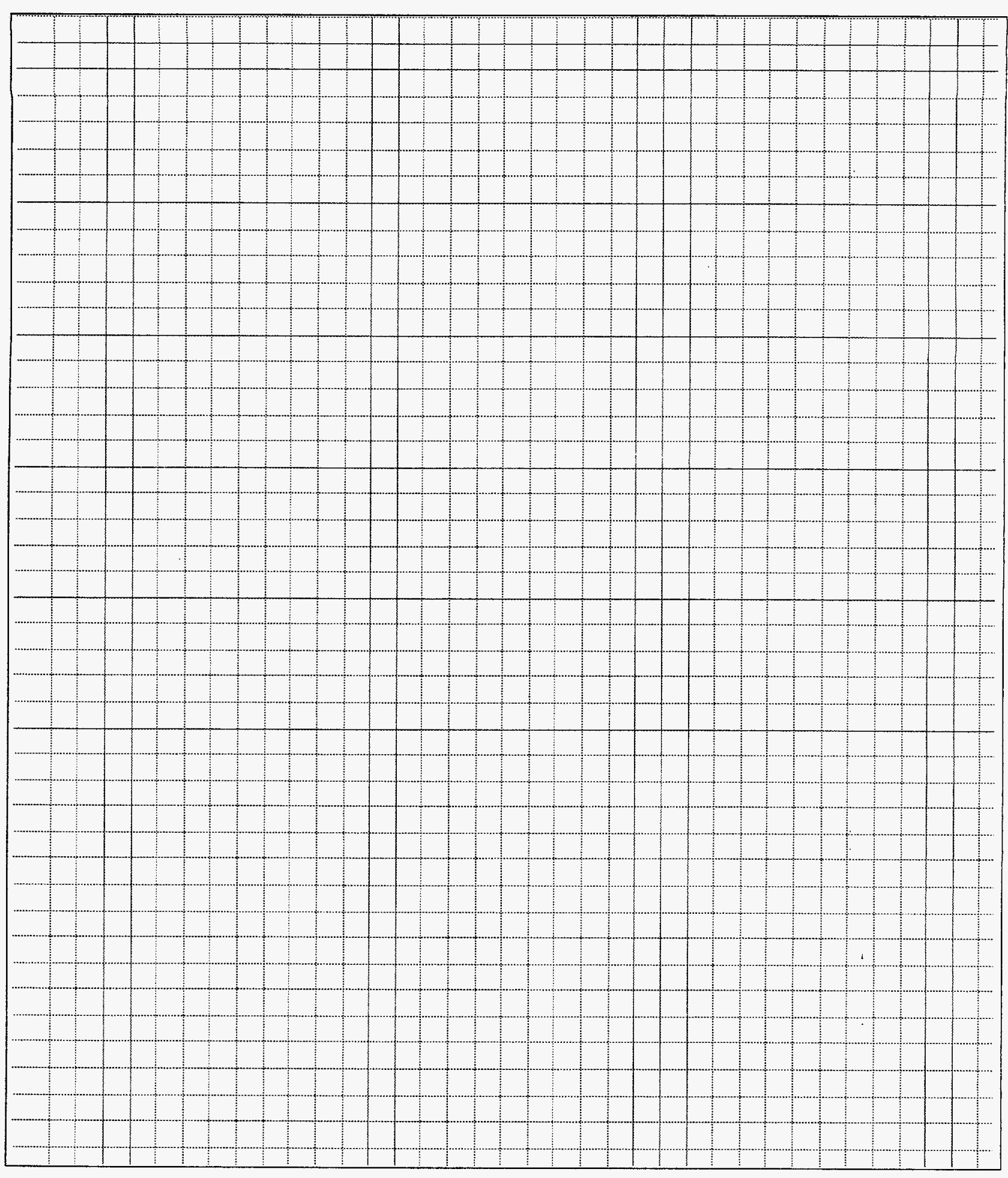

